\title{
Article \\ The Effect of Laser Nitriding on Surface Characteristics and Wear Resistance of NiTi Alloy with Low Power Fiber Laser
}

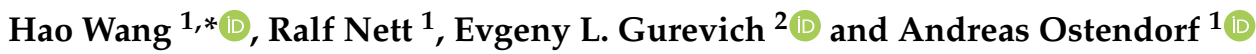 \\ 1 Chair of Applied Laser Technologies, Ruhr-Universität Bochum, 44801 Bochum, Germany; \\ nett@lat.rub.de (R.N.); andreas.ostendorf@ruhr-uni-bochum.de (A.O.) \\ 2 Laser Center-LFM, Münster University of Applied Sciences, 48565 Steinfurt, Germany; \\ gurevich@fh-muenster.de \\ * Correspondence: hao.wang-p6i@ruhr-uni-bochum.de
}

Citation: Wang, H.; Nett, R.;

Gurevich, E.L.; Ostendorf, A. The

Effect of Laser Nitriding on Surface Characteristics and Wear Resistance of NiTi Alloy with Low Power Fiber Laser. Appl. Sci. 2021, 11, 515. https://doi.org/10.3390/app11020515

Received: 6 December 2020

Accepted: 4 January 2021

Published: 7 January 2021

Publisher's Note: MDPI stays neutral with regard to jurisdictional clai$\mathrm{ms}$ in published maps and institutional affiliations.

Copyright: (C) 2021 by the authors. Licensee MDPI, Basel, Switzerland. This article is an open access article distributed under the terms and conditions of the Creative Commons Attribution (CC BY) license (https:// creativecommons.org/licenses/by/ $4.0 /)$.

\begin{abstract}
The laser nitriding was performed in nitrogen gas at room temperature $\left(20^{\circ} \mathrm{C}\right)$ and low temperature $\left(-190^{\circ} \mathrm{C}\right)$ by a low power fiber laser to modify the wear and abrasion resistance of NiTi alloy. The surface roughness and element composition were analyzed by roughness device and energy-dispersive $\mathrm{X}$-ray spectroscopy respectively. The results of roughness show that laser treatment can change the surface roughness due to the laser remelting. The effect of laser nitriding on the microhardness, friction coefficient, and worn scars of NiTi alloy was also studied, which shows that the microhardness of the NiTi alloy increases after laser nitriding. The optical microscope and scanning electron microscope were used to characterize the surface of NiTi alloy after wear testing to observe the microstructure of worn scars. The results show that the laser nitriding with different parameters can induce a nitride layer with different thicknesses and the higher energy deposition is the key factor for the formation of the nitride layer, which can decrease the friction coefficient and reduce wear loss during the application of NiTi alloy. The improvement of wear resistance can be attributed to the hard nitriding layer.
\end{abstract}

Keywords: laser nitriding; wear resistance; NiTi alloy; roughness; microhardness

\section{Introduction}

With the development of medical science and technology, there are increasing requirements for implanted materials that can replace or assist the natural organs of humans [1], like stents, heart valves, bones, skull, and knee implant metals. Materials that are of interest for this application are 316L steel, pure titanium, and nickel-titanium (NiTi) alloy [2-4]. The nickel-titanium (NiTi) alloy has been widely investigated to consider as materials that can be used as medical implants in the body, which is due to its good mechanical performance and shape memory effect [5]. The lower modulus of NiTi alloy is also beneficial for its medical application, such as accelerating bone healing and reducing bone shielding effects [6]. Due to the generation of wear and abrasion during the application as the bone of NiTi alloy in the human body, it is necessary to replace the implanted joints within 15-20 years [7]. Hence, the wear property plays an important role in joint replacement and these candidate applications need good surface wear property [8]. Many surface modification treatments have been studied to improve the surface corrosion, wear, and abrasion resistance of NiTi alloy to extend its service life, including ion implantation, shot peening, and so on $[9,10]$. Hu et al. used the surface mechanical attrition treatment (SMAT) to induce grain refinement on the top layer of NiTi alloy, which shows that the friction coefficient decreased and the wear resistance was improved after surface treatment with mechanical attrition [11]. Li et al. demonstrated that the NiTi alloy treated by $\mathrm{Nb}$ ion implantation would have a lower surface coefficient of fiction and fewer worn debris during wear testing [12]. Zhang et al. studied the effect of laser shock peening on the corrosion resistance and surface mechanical property of NiTi alloy and they found that the 
laser shock peening can increase the surface microhardness and enhance the mechanical property (such as wear-resistance) of NiTi alloy [13]. In our previous research, we also got similar results when the metals, such as aluminum, high strength, and NiTi alloy, were processed with laser shock peening [14-16]. In this research, the laser nitriding process with fiber laser was used to modify the surface mechanical property of NiTi alloy to enhance its wear and abrasion resistance. The laser beam irradiates on the surface of the substrate in a chamber filled with nitrogen gas, which would heat the metal surface to the temperature of the melting point. The above interaction can induce nitrogen ions and atoms to be bound on the surface and help the formation of the TiN layer [17]. Lisiecki produced a TiN layer on the surface of the Ti6Al4V alloy with a high power direct diode laser [18] and found that the microhardness is up to $2400 \mathrm{HV}_{0.2}$ on top of the Ti6Al4V alloy. Zeng et al. used laser nitriding to process a pure titanium sample that can improve its biocompatibility and corrosion resistance [19]. In this work, the NiTi alloy would be processed with low power fiber laser in nitrogen gas at different temperatures (room temperature (RT) about $20^{\circ} \mathrm{C}$ and low temperature (LT) about $-190^{\circ} \mathrm{C}$ ) to produce a TiN layer. The effect of laser nitriding on the surface roughness, microhardness and wear resistance of NiTi alloy is also investigated before and after the treatment.

\section{Materials and Methods}

NiTi alloy samples from Ingpuls $\mathrm{GmbH}$ were processed by laser nitriding in nitrogen gas. The NiTi alloy sample was cut into $20 \mathrm{~mm} \times 10 \mathrm{~mm}$ with a thickness of $1 \mathrm{~mm}$. The NiTi alloy samples were cleaned in ethanol before and after laser processing. The laser nitriding process was done in the chamber as shown in Figure 1, in which the sample was placed on the holder made from copper. The laser beam can pass through the cover with a small window glued with thin glass. The nitrogen gas can enter the chamber through the upper vent and exit through the below vent with stable pressure of $2 \mathrm{Mbar}$. The fiber laser (FLR-50-SC-OEM) with a power of $50 \mathrm{~W}$ was used in the pulse mode in the present research. The samples were in the gas chamber and processed at room temperature (about $20^{\circ} \mathrm{C}$ ) and low temperature (liquid nitrogen temperature, about $-190^{\circ} \mathrm{C}$ ) with different laser parameters as shown in the Table 1 . The diameter of the laser spot was about $170 \mu \mathrm{m}$ and the overlapping of scanning lines was $76 \%$ during the laser process. The highest backside temperature of the NiTi sample during the laser nitriding was measured by a temperature meter (GTH 1150). After laser treatment and wear testing, the surface images of NiTi were observed with Scanning Electron Microscope (SEM-Zeiss EVO MA 15) and optical microscopy in this research. The microhardness along the cross-section of NiTi alloy after laser nitriding was measured with the KB 30 BVZ hardness device (load force of $100 \mathrm{~g}$ and load time of $10 \mathrm{~s}$ ). The surface roughness of NiTi before and after laser nitriding was tested with Ra (arithmetical mean deviation of the profile) and $\mathrm{Rz}$ (the point height of irregularities) with mobile roughness measurement devices of Perthometer M1 (Mahr) which is an important factor for wear and abrasion property of the NiTi alloy. The wear and abrasion testing were performed with a reciprocating ball-on-plate machine (UMT

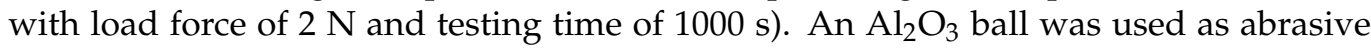
ceramic specimens during the testing at room temperature. 


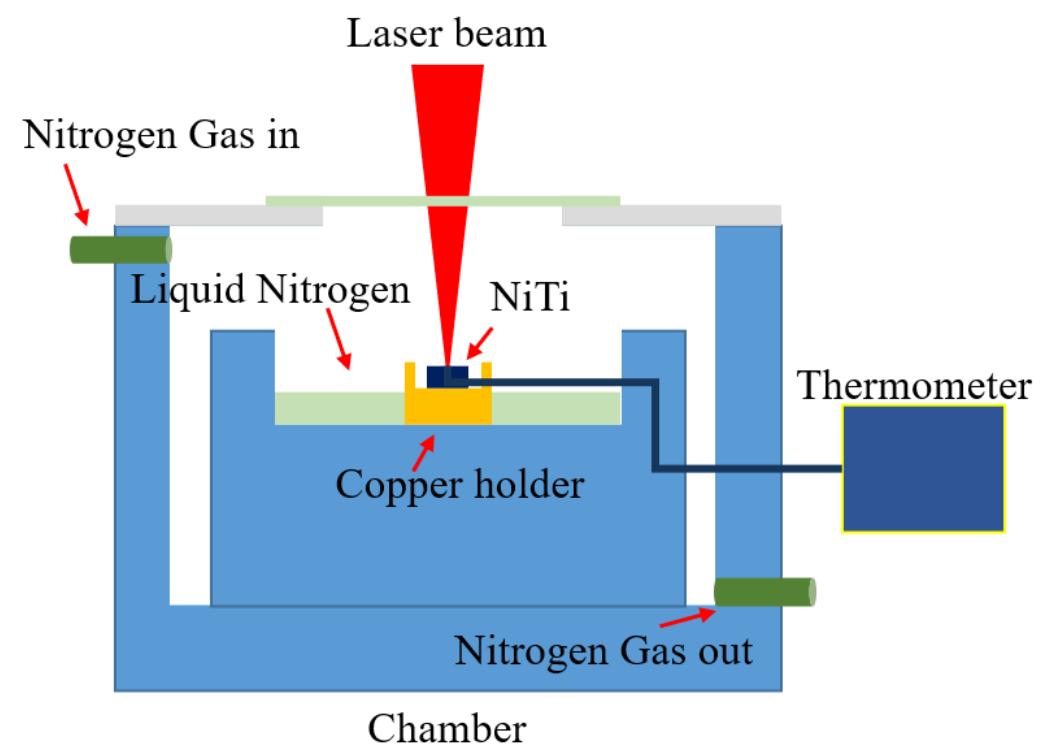

Figure 1. The schematic diagram of the laser nitriding process on NiTi alloy.

Table 1. The laser parameter for different NiTi samples.

\begin{tabular}{cccccc}
\hline Samples & $\begin{array}{c}\text { Scanning } \\
\text { Speed }\end{array}$ & Frequency & $\begin{array}{c}\text { Nitrogen } \\
\text { Gas Pressure }\end{array}$ & $\begin{array}{c}\text { Process } \\
\text { Temperature }\end{array}$ & $\begin{array}{c}\text { Highest } \\
\text { Temperature }\end{array}$ \\
\hline S-1 & - & - & - & $20{ }^{\circ} \mathrm{C}$ & $20{ }^{\circ} \mathrm{C}$ \\
S-2 & $80 \mathrm{~mm} / \mathrm{s}$ & $100 \mathrm{KHz}$ & $2 \mathrm{Mbar}$ & $20{ }^{\circ} \mathrm{C}$ & $90{ }^{\circ} \mathrm{C}$ \\
$\mathrm{S}-3$ & $40 \mathrm{~mm} / \mathrm{s}$ & $200 \mathrm{KHz}$ & $2 \mathrm{Mbar}$ & $20{ }^{\circ} \mathrm{C}$ & $240^{\circ} \mathrm{C}$ \\
S-4 & $40 \mathrm{~mm} / \mathrm{s}$ & $200 \mathrm{KHz}$ & $2 \mathrm{Mbar}$ & $-190{ }^{\circ} \mathrm{C}$ & $120^{\circ} \mathrm{C}$ \\
\hline
\end{tabular}

\section{Results}

When the laser beam irradiated the surface of NiTi samples, the surface temperature would rise very fast. The highest temperature of the NiTi sample on its backside was measured during the laser nitriding. It can be found that the backside temperature of S-3 during laser nitriding was the highest (about $240^{\circ} \mathrm{C}$ ). The temperatures of other NiTi alloy of S-2 and S-4 were about $90{ }^{\circ} \mathrm{C}$ and $120^{\circ} \mathrm{C}$, which wwas much lower than that of S-3. Figure 2 shows the SEM images and energy dispersive X-ray (EDX) mapping results of a single laser scanning line on the surface of NiTi targets with different laser parameters and temperatures. From the SEM images, it can be found that no cracks are appearing on the surface of NiTi alloy after laser nitriding treatment. Because of the Gaussian profile of the laser beam, the melt track can be observed in the center of the laser scanning area. From the EDX mapping, the elements of Ti and N (bright area) were mainly concentrated in the central part of the laser spot in the scanning lines, which is because of the remelting in the special area. Due to the laser remelting, the roughness of the treated region is higher than that of the untreated surface. Figure 3 shows the roughness of NiTi alloy after laser nitriding with different laser parameters. The Ra and $\mathrm{Rz}$ of untreated NiTi alloy were $0.13 \pm 0.03 \mu \mathrm{m}$ and $0.83 \pm 0.22 \mu \mathrm{m}$ respectively. The Ra of S-2, S-3, and S-4 are $1.05 \pm 0.15 \mu \mathrm{m}, 0.39 \pm 0.04 \mu \mathrm{m}$, and $0.84 \pm 0.22 \mu \mathrm{m}$ respectively. The Rz of S-2, S-3, and $\mathrm{S}-4$ are $6.81 \pm 0.44 \mu \mathrm{m}, 3.98 \pm 0.27 \mu \mathrm{m}$, and $5.87 \pm 0.73 \mu \mathrm{m}$ respectively. The roughness of S-3 was higher than as-received NiTi alloy, but it was lower than that of other samples with different laser nitriding parameters. 


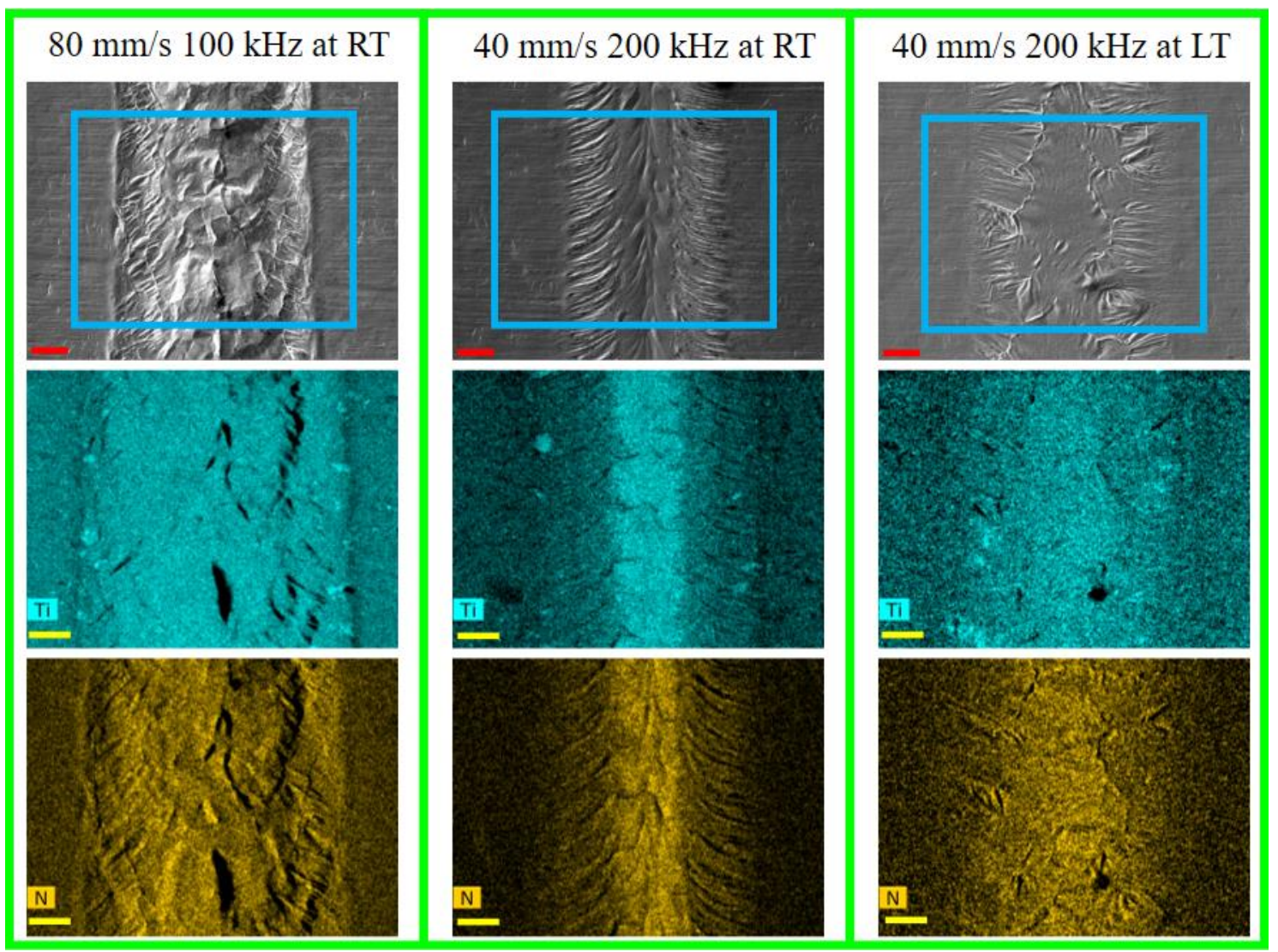

Figure 2. The SEM images and EDX mapping results on the surface of NiTi alloy after single laser scanning (red scale bar: $40 \mu \mathrm{m}$ and yellow: $40 \mu \mathrm{m}$ ). Laser processing parameters (scanning velocity, laser repetition rate, temperature) were given in the first row of the table. RT stays for the room temperature, LT-for process with liquid nitrogen temperature.

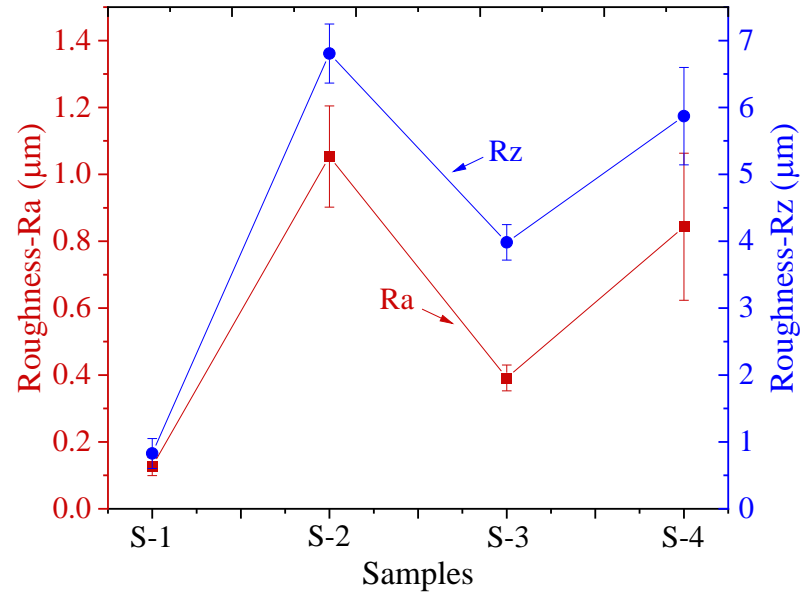

Figure 3. The surface roughness of NiTi alloy before and after laser nitriding.

Figure 4 shows the SEM images along the cross-section of NiTi targets after laser nitriding with different parameters. The thickness of the melted zone of the laser nitriding in the top layer of NiTi alloy was different when it was treated with different laser parameters. Both melted layers of S-2 and S- 4 were less than $10 \mu \mathrm{m}$. The thickness of the laser nitride layer of S-3 was about $65 \mu \mathrm{m}$ due to its slow scanning speed and higher laser repetition. The elemental analysis was measured with energy-dispersive X-ray spectroscopy and the positions were marked in Figure 4. Table 2 shows the element resulting in different positions of the NiTi alloy. It can be noted that the sample of S-3 that was treated with 
$40 \mathrm{~mm} / \mathrm{s}$ and $200 \mathrm{kHz}$ at room temperature could induce a deeper layer with the TiN. The reason is that the surface temperature is a very important factor for the formation of the nitride layer during the laser nitriding. Moreover, from sample S-3, processed at room temperature with $40 \mathrm{~mm} / \mathrm{s}$ and $200 \mathrm{kHz}$ in Figure 2, we can see the periodic corrugation, evidencing the Marangoni-induced convection flow. This flow induces convective mixing and hence, an additional mechanism responsible for the transport of TiN from the surface into the volume of the sample at a depth comparable to the depth of the molten pool. From Table 1, it can be found that the highest back temperature (about $240{ }^{\circ} \mathrm{C}$ ) of NiTi alloy during the laser nitriding process is the NiTi alloy (S-3) treated by $40 \mathrm{~mm} / \mathrm{s}$ and $200 \mathrm{kHz}$ at room temperature, which means that the more energy deposition at room temperature is an effective method to induce deeper nitride layer for NiTi alloy.
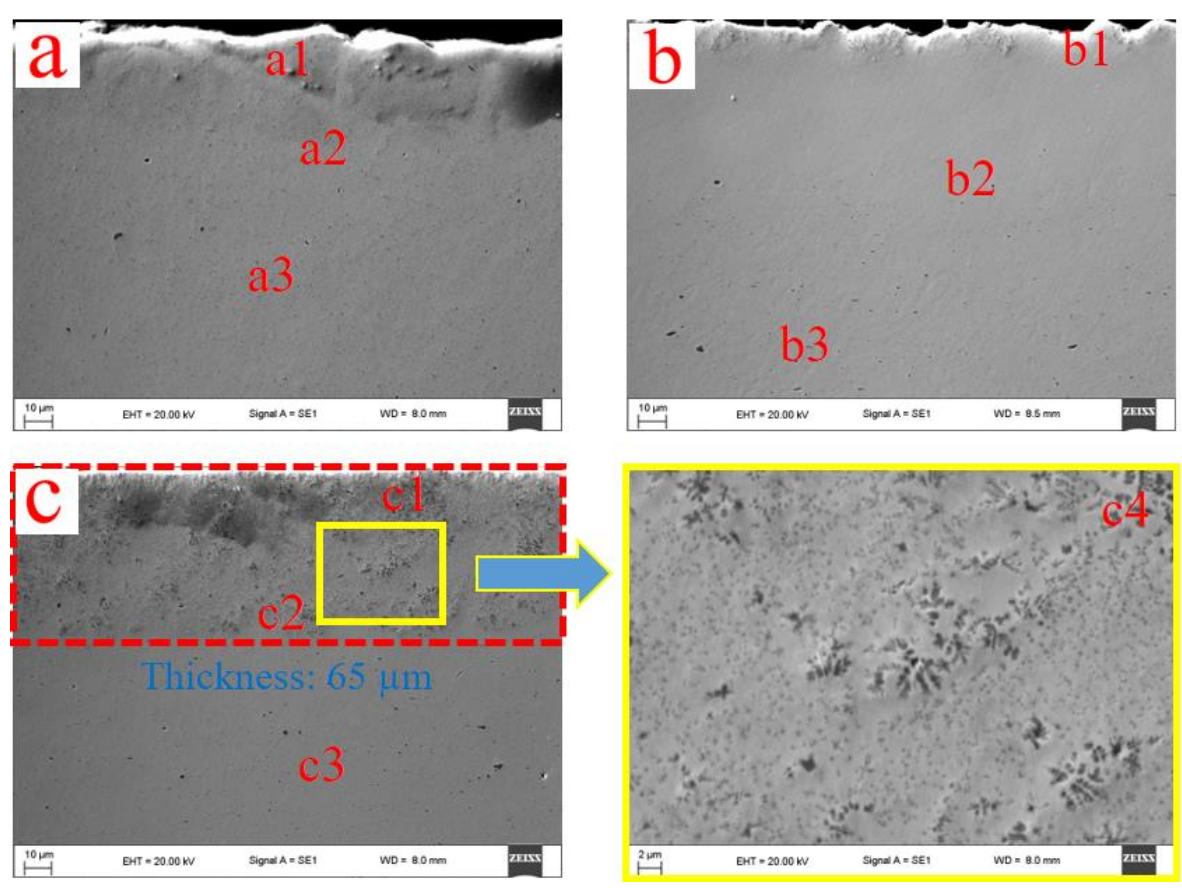

Figure 4. The cross-section SEM images of NiTi alloy after laser nitriding: (a) laser nitriding with a scanning speed of $80 \mathrm{~mm} / \mathrm{s}$ and frequency of $100 \mathrm{kHz}$ at room temperature (sample S-2), (b) laser nitriding with a scanning speed of $40 \mathrm{~mm} / \mathrm{s}$, and frequency of $200 \mathrm{kHz}$ at low temperature (sample S-4). (c) laser nitriding with a scanning speed of $40 \mathrm{~mm} / \mathrm{s}$ and a frequency of $200 \mathrm{kHz}$ at room temperature (sample S-3).

Table 2. The EDX elemental analysis along the cross-section of the NiTi alloy after laser nitriding (marked in Figure 4, At\%).

\begin{tabular}{cccccccc}
\hline Positions & $\mathbf{O}$ & $\mathbf{C}$ & $\mathbf{N}$ & $\mathbf{T i}$ & $\mathbf{N i}$ & $\mathbf{B a}$ & $\mathbf{T a}$ \\
\hline a1 & 4.67 & 43.44 & 1.79 & 20.52 & 22.43 & 6.25 & 0.90 \\
a2 & - & 7.70 & - & 35.21 & 44.60 & 10.70 & 1.78 \\
a3 & - & 7.77 & - & 35.83 & 43.87 & 10.78 & 1.75 \\
\hline b1 & - & 4.81 & - & 34.98 & 43.90 & 10.93 & 1.78 \\
b2 & - & 7.31 & - & 36.17 & 43.65 & 11.12 & 1.74 \\
b3 & - & 7.46 & - & 35.44 & 44.41 & 10.92 & 1.77 \\
\hline c1 & - & 13.29 & 16.25 & 33.47 & 25.69 & 10.32 & 0.98 \\
c2 & - & 6.01 & 8.55 & 38.38 & 33.72 & 11.95 & 1.38 \\
c3 & - & 7.35 & - & 35.98 & 43.94 & 10.92 & 1.81 \\
c4 & - & 5.00 & 14.43 & 40.23 & 26.80 & 12.42 & 1.11 \\
\hline
\end{tabular}


The microhardness along the cross-section of the NiTi sample was measured as shown in Figure 5. The hardness of the base sample was less than $350 \mathrm{HV}$ when the load force is $100 \mathrm{~g}$ during hardness measurement. The hardness results show that the gradient of hardness can be found along the cross-section of NiTi alloy after the laser nitriding. The top layer has the highest hardness for different laser parameters. It can be observed that the highest hardness of NiTi alloy (S-3) treated with a scanning speed of $40 \mathrm{~mm} / \mathrm{s}$ and a frequency of $200 \mathrm{kHz}$ at room temperature is $569 \pm 25 \mathrm{HV}$, which is much higher than that of the base material. The higher hardness of the S-3 sample is attributed to the distribution of the TiN layer with a larger thickness. The laser nitriding is a heat-treatment process that can induce the diffusion of nitrogen into the subsurface of NiTi alloy to enhance its surface mechanical property. From Table 1, it can be found that laser nitriding with a scanning speed of $40 \mathrm{~mm} / \mathrm{s}$ and a frequency of $200 \mathrm{kHz}$ at room temperature can induce higher temperature in the treated area and generate a thicker and harder TiN layer. Normally, the hardness can be used as the criteria for judging the wear and abrasion resistance of alloys and the higher hardness can induce better wear resistance.

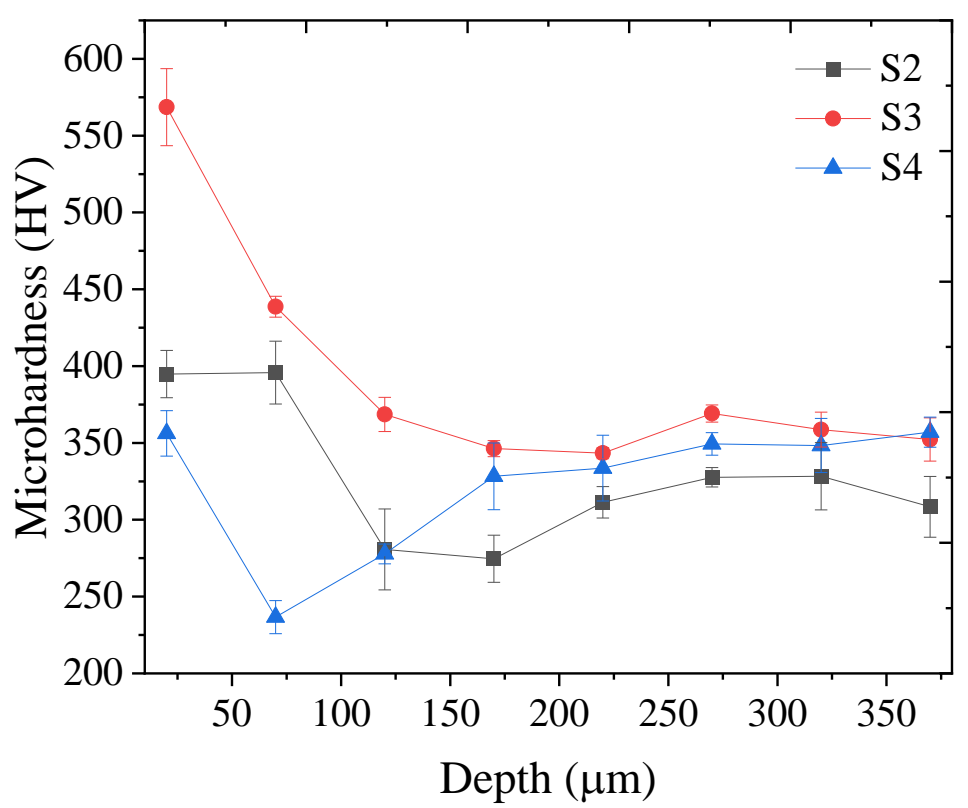

Figure 5. Microhardness along the cross-section of NiTi alloy after laser nitriding.

Since the body implants made of NiTi alloy have to be replaced after their service life due to their wear and abrasion, it is important to enhance and improve their surface wear and abrasion resistance. The wear property of NiTi is measured before and after laser nitriding treatment to study the effect of laser nitriding on the wear resistance of NiTi alloy. The coefficient of fiction of NiTi alloy can be used to represent its wear property during wear testing. Figure 6 presents the relationship between the coefficient of friction and wear time on the NiTi alloy with different laser nitriding treatment. It can be seen that the coefficient of friction of sample S- 4 treated by laser nitriding with a scanning speed of $40 \mathrm{~mm} / \mathrm{s}$ and frequency of $200 \mathrm{kHz}$ at low temperature is similar to that of untreated NiTi alloy sample with a friction coefficient of 0.74 . The reason for the results is that the thickness of the melted layer is very thin. The friction coefficient of sample S-2 treated by laser nitriding with a scanning speed of $80 \mathrm{~mm} / \mathrm{s}$ and frequency of $100 \mathrm{kHz}$ was lower than that of the untreated sample and increased gradually to around 0.74 at the fretting time of $100 \mathrm{~s}$. The friction coefficient of sample S-3 treated by laser nitriding with $40 \mathrm{~mm} / \mathrm{s}$ and $200 \mathrm{kHz}$ at room temperature increased from 0.20 to 0.40 at the fretting time of $50 \mathrm{~s}$ and became stable with a friction coefficient of 0.4 after a fretting time of $50 \mathrm{~s}$. As can be seen, the friction coefficient of NiTi alloy (S-3) treated with $40 \mathrm{~mm} / \mathrm{s}$ and $200 \mathrm{kHz}$ at room temperature is significantly lower compared to other samples. The lower friction coefficient 
confirms that the laser nitriding with special parameters can increase the wear resistance of NiTi alloy. Figure 7 shows the optical microscope images of the worn scars on the surface of the NiTi alloy processed with different laser nitriding parameters, from which it can be found that the width of worn scars become smaller after laser treatment. The widths of worn scars of S-1, S-2, and S-4 were $464 \pm 6 \mu \mathrm{m}, 451 \pm 8 \mu \mathrm{m}$, and $453 \pm 5 \mu \mathrm{m}$ respectively. However, the worn width of NiTi alloy (S-3) with laser nitriding of $40 \mathrm{~mm} / \mathrm{s}$ and $200 \mathrm{kHz}$ at room temperature has the narrowest width of $114 \pm 9 \mu \mathrm{m}$ compared with that of the untreated NiTi sample (464 $\pm 6 \mu \mathrm{m})$, which means that the worn width of NiTi decreased by $75 \%$ after laser nitriding treatment with the special process parameters. The enhanced surface microhardness and TiN layer were the main reason for the improvement of wear resistance.

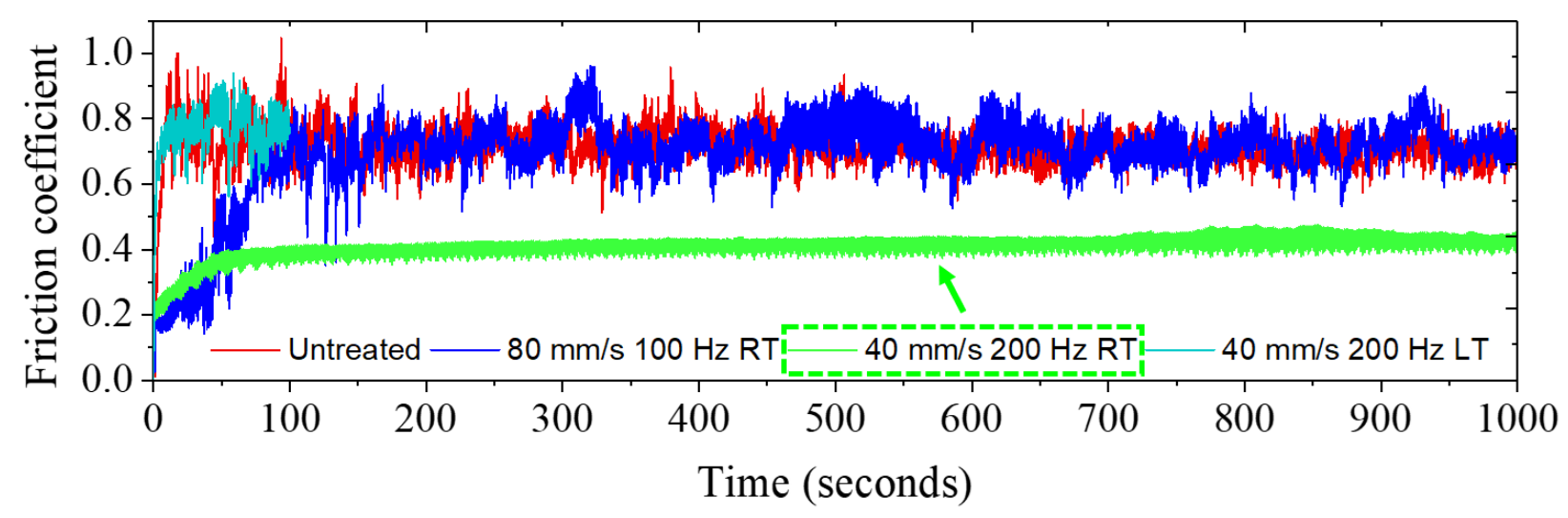

Figure 6. The friction coefficient with a wear time of NiTi alloy with different laser nitriding parameters.
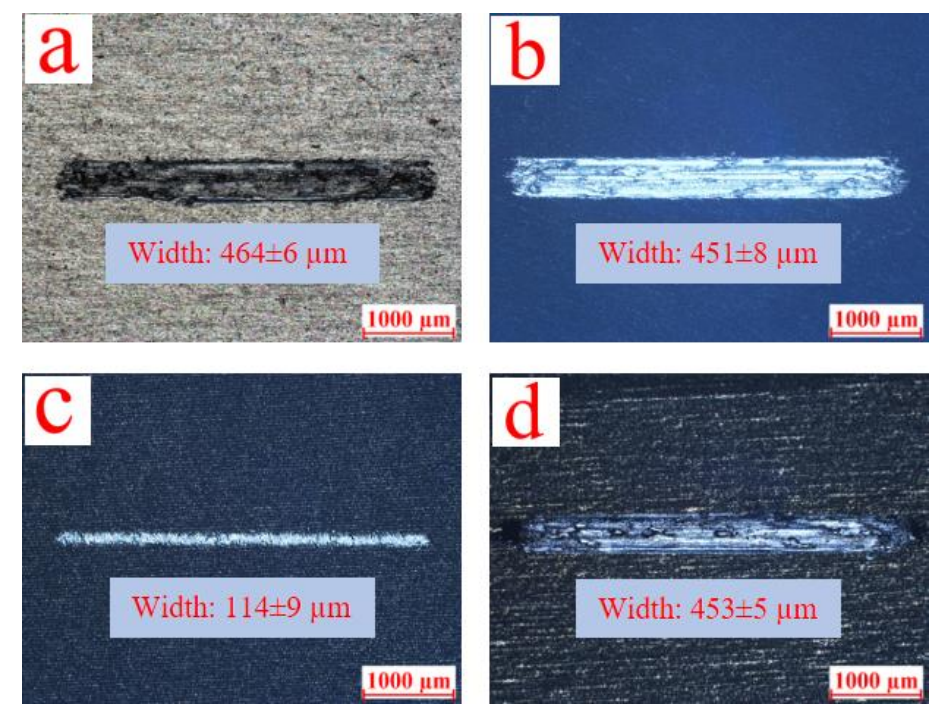

Figure 7. The optical surface images of worn scars on the NiTi alloy with and without laser nitriding (a) untreated (sample S-1) (b). Laser nitriding with scanning speed of $80 \mathrm{~mm} / \mathrm{s}$ and frequency of $100 \mathrm{kHz}$ at room temperature (sample S-2) (c) laser nitriding with scanning speed of $40 \mathrm{~mm} / \mathrm{s}$, and frequency of $200 \mathrm{kHz}$ at room temperature (sample S-3). (d) Laser nitriding with a scanning speed of $40 \mathrm{~mm} / \mathrm{s}$ and a frequency of $200 \mathrm{kHz}$ at low temperature (sample S-4).

Figure 8 shows the SEM images of untreated and laser nitride NiTi samples (S-3: $40 \mathrm{~mm} / \mathrm{s}$ and $200 \mathrm{kHz}$ at room temperature). The particles with a small size can be observed in the worn area of untreated NiTi alloy. However, the worn area of treated NiTi alloy was very smooth and there were no worn particles due to the nitride layer. The movement of implant material-NiTi used as artificial joints would produce lots of 
small-sized particles which can be found in the blood. The laser nitriding can be used to decrease the abrasion spallation and cracking so that the NiTi joints can be used for a longer time. It can be found that the wear mechanisms of NiTi alloy after laser nitriding is different from that of untreated specimens. The $\mathrm{Al}$ element and more $\mathrm{O}$ element were found in the area of the untreated NiTi alloy in worn scars (as shown in Table 3) when the EDX measurement (positions a1, a2, b1, and b2 marked in Fig. 8) was used to analyze the elemental composition, which is due to the $\mathrm{Al}_{2} \mathrm{O}_{3}$ particles fall from the $\mathrm{Al}_{2} \mathrm{O}_{3}$ ball during the wear testing. However, there was no $\mathrm{Al}$ element observed on the surface of nitriding $\mathrm{NiTi}$ alloy-worn scars, which is due to the fact that the nitriding layer can decrease the friction coefficient. Figure $8 \mathrm{~b}$ also shows that the only minor wear occurred and there are no cracks in the worn scars of nitriding NiTi alloy. There was no Al element from the EDX testing on the worn scar of NiTi alloy after laser nitriding because the laser nitriding induces a lower friction coefficient which would not generate severe wear.
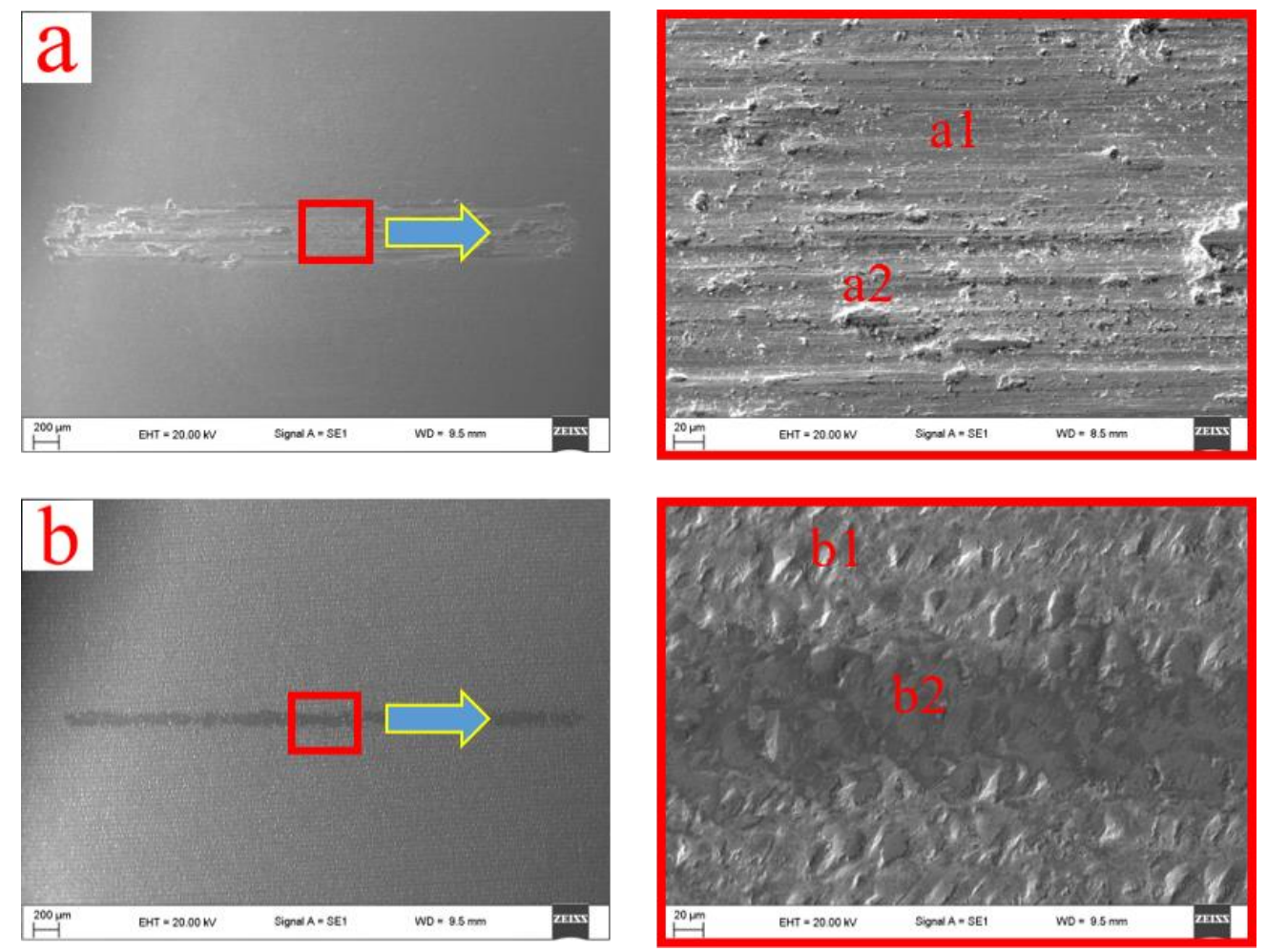

Figure 8. The SEM worn scar images of NiTi alloy, (a) untreated (sample S-1), and (b) laser nitriding with the laser a scanning speed of $40 \mathrm{~mm} / \mathrm{s}$ and frequency of $200 \mathrm{kHz}$ at room temperature (sample S-3).

Table 3. The EDX elemental analysis in the worn scars of the NiTi alloy (marked in Figure 8, At\%).

\begin{tabular}{ccccccccc}
\hline Positions & $\mathbf{C}$ & $\mathbf{N}$ & $\mathbf{O}$ & $\mathbf{A l}$ & $\mathbf{T i}$ & $\mathbf{N i}$ & $\mathbf{B a}$ & Ta \\
\hline a1 & 4.59 & - & 29.81 & 3.42 & 25.16 & 29.73 & 6.26 & 1.03 \\
a2 & 18.12 & - & 17.21 & 2.95 & 25.11 & 29.42 & 6.16 & 1.03 \\
\hline b1 & 9.48 & 10.48 & 3.77 & - & 32.31 & 33.79 & 8.88 & 1.29 \\
b2 & 4.57 & 15.24 & 8.00 & - & 33.67 & 27.98 & 9.37 & 0.99 \\
\hline
\end{tabular}

\section{Conclusions}

The NiTi alloy was processed by laser nitriding with different process parameters and the surface abrasion property of samples was studied. The surface laser nitriding treatment can increase the surface roughness of the NiTi alloy due to the laser ablation by the instant high temperature of a laser beam. The microhardness and elemental composition along the cross-section of the NiTi alloy were also analyzed, which shows that the hardness was 
increased after laser nitriding treatment. The friction coefficient and wear resistance of $\mathrm{NiTi}$ alloy were also improved after laser nitriding. The results indicated that the laser nitriding with $40 \mathrm{~mm} / \mathrm{s}$ and $200 \mathrm{kHz}$ at room temperature can produce the best nitride layer with a thickness of $65 \mu \mathrm{m}$ to modify the wear resistance of NiTi alloy compared to experiments with other processing parameters. The energy deposition and temperature of NiTi alloy are very important factors that can influence the formation of the nitride layer during the laser nitriding process. The largest thickness of the TiN layer and the highest surface wear resistance can be observed at parameters corresponding to the highest energy deposition rate and hence to the highest surface temperature of the processed NiTi alloy. The morphology of the surface indicates stable convection in the melt pool in this case. These two facts evidence that the enrichment of the deeper layer with nitrogen ions needed for the nitride formation happens through both convection and diffusion mechanisms.

Author Contributions: Experimental design and data analysis, H.W.; writing-original draft preparation, H.W.; equipment preparation, H.W. and R.N.; writing-review and editing, E.L.G.; project administration, A.O. All authors have read and agreed to the published version of the manuscript.

Funding: This research was funded by the China Scholarship Council (CSC, No. 201706340042).

Institutional Review Board Statement: Not applicable.

Informed Consent Statement: Not applicable.

Data Availability Statement: The data presented in this study are available on request from the corresponding author.

Conflicts of Interest: The authors declare no conflict of interest.

\section{References}

1. Prakasam, M.; Locs, J.; Salma-Ancane, K.; Loca, D.; Largeteau, A.; Berzina-Cimdina, L. Biodegradable materials and metallic implants-A review. J. Funct. Biomater. 2017, 8, 44. [CrossRef] [PubMed]

2. Man, H.C.; Wang, Q.; Guo, X. Laser surface microdrilling of Ti and laser gas nitrided Ti for enhancing fixation of dental implants. Opt. Lasers Eng. 2010, 48, 583-588. [CrossRef]

3. Hung, C.-H.; Chang, F.-Y.; Chang, T.-L.; Chang, Y.-T.; Huang, K.-W.; Liang, P.-C. Micromachining NiTi tubes for use in medical devices by using a femtosecond laser. Opt. Lasers Eng. 2015, 66, 34-40. [CrossRef]

4. Shi, Z.; Zhou, Z.; Shum, P.; Li, L.K.-Y. Thermal stability, wettability and corrosion resistance of sputtered ceria films on 316 stainless steel. Appl. Surf. Sci. 2019, 477, 166-171. [CrossRef]

5. $\quad \mathrm{Ng}, \mathrm{C} . \mathrm{H}$;; Chan, O.K.; Man, H.C. Formation of TiN grid on NiTi by laser gas nitriding for improving wear resistance in Hanks' solution. J. Mater. Sci. Technol. 2016, 32, 459-464. [CrossRef]

6. $\mathrm{Ng}$, C.H.; Chan, C.W.; Man, H.C.; Waugh, D.G.; Lawrence, J. NiTi shape memory alloy with enhanced wear performance by laser selective area nitriding for orthopaedic applications. Surf. Coat. Technol. 2017, 309, 1015-1022. [CrossRef]

7. Zhao, T.; Li, Y.; Liu, Y.; Zhao, X. Nano-hardness, wear resistance and pseudoelasticity of hafnium implanted NiTi shape memory alloy. J. Mech. Behav. Biomed. Mater. 2012, 13, 174-184. [CrossRef] [PubMed]

8. Zhao, N.Q.; Man, H.C.; Cui, Z.D.; Yang, X.J. Structure and wear properties of laser gas nitrided NiTi surface. Surf. Coat. Technol. 2006, 200, 4879-4884. [CrossRef]

9. Oliveira, R.M.; Fernandes, B.B.; Carreri, F.C.; Gonçalves, J.A.N.; Ueda, M.; Silva, M.; Silva, M.M.; Pichon, L.; Camargo, E.N.; Otubo, J. Surface modification of NiTi by plasma based ion implantation for application in harsh environments. Appl. Surf. Sci. 2012, 263, 763-768. [CrossRef]

10. Sui, J.H.; Cai, W. Formation of diamond-like carbon (DLC) film on the NiTi alloys via plasma immersion ion implantation and deposition (PIIID) for improving corrosion resistance. Appl. Surf. Sci. 2006, 253, 2050-2055. [CrossRef]

11. Hu, T.; Wen, C.S.; Sun, G.Y.; Wu, S.L.; Chu, C.L.; Wu, Z.W.; Li, G.Y.; Lu, J.; Yeung, K.W.K.; Chu, P.K. Wear resistance of NiTi alloy after surface mechanical attrition treatment. Surf. Coat. Technol. 2010, 205, 506-510. [CrossRef]

12. Li, Y.; Zhang, F.; Zhao, T.-T.; Tang, M.; Liu, Y. Enhanced wear resistance of NiTi alloy by surface modification with Nb ion implantation. Rare Met. 2014, 33, 244-248. [CrossRef]

13. Zhang, R.; Mankoci, S.; Walters, N.; Gao, H.; Zhang, H.; Hou, X.; Qin, H.; Ren, Z.; Zhou, X.; Doll, G.L. Effects of laser shock peening on the corrosion behavior and biocompatibility of a nickel-titanium alloy. J. Biomed. Mater. Res. Part B Appl. Biomater. 2019, 107, 1854-1863. [CrossRef] [PubMed]

14. Wang, H.; Huang, Y.; Zhang, W.; Ostendorf, A. Investigation of multiple laser shock peening on the mechanical property and corrosion resistance of shipbuilding 5083Al alloy under a simulated seawater environment. Appl. Opt. 2018, 57, 6300-6308. [CrossRef] [PubMed] 
15. Wang, H.; Kalchev, Y.; Wang, H.; Yan, K.; Gurevich, E.L.; Ostendorf, A. Surface modification of NiTi alloy by ultrashort pulsed laser shock peening. Surf. Coat. Technol. 2020, 394, 125899. [CrossRef]

16. Wang, H.; Keller, S.; Bai, Y.; Kashaev, N.; Gurevich, E.L.; Ostendorf, A. Laser shock peening on high-strength steel. In Proceedings of the Advanced Laser Processing and Manufacturing IV; International Society for Optics and Photonics, Singapore, 29 June-2 July 2020; Volume 11546, p. 115460L.

17. Chan, C.-W.; Lee, S.; Smith, G.C.; Donaghy, C. Fibre laser nitriding of titanium and its alloy in open atmosphere for orthopaedic implant applications: Investigations on surface quality, microstructure and tribological properties. Surf. Coat. Technol. 2017, 309, 628-640. [CrossRef]

18. Lisiecki, A. Titanium matrix composite Ti/TiN produced by diode laser gas nitriding. Metals 2015, 5, 54-69. [CrossRef]

19. Zeng, C.; Wen, H.; Ettefagh, A.H.; Zhang, B.; Gao, J.; Haghshenas, A.; Raush, J.R.; Guo, S.M. Laser nitriding of titanium surfaces for biomedical applications. Surf. Coat. Technol. 2020, 385, 125397. [CrossRef] 